\title{
Remote sensing observations of the coherent and non-coherent ring structures in the vicinity of Lesser Antilles
}

\author{
R. C. Cruz Gómez ${ }^{1}$ and S. N. Bulgakov ${ }^{2}$ \\ ${ }^{1}$ Posgrado de Ciencias del Mar y Limnologia, Universidad Nacional Autonoma de Mexico, Mexico \\ ${ }^{2}$ Institute of Astronomy and Meteorology, Guadalajara University, Mexico
}

Received: 10 November 2006 - Revised: 19 January 2007 - Accepted: 26 January 2007 - Published: 8 March 2007

\begin{abstract}
The North Brazil Current Rings (NBCR) penetration into the Caribbean Sea is being investigated by employing a merged altimeter-derived sea height anomaly (TOPEX/Poseidon, Jason-1 and ERS-1, 2), the ocean surface color data (SeaWiFS) and Global Drifter Program information. Four strategies are being applied to process the data: (1) calculations of the Okubo-Weiss parameter for NBCR identification, (2) longitude-time plots (also known as Hovmöller diagrams), (3) two-dimensional Radon transforms and (4) two-dimensional Fourier transforms.

A twofold NBCR structure has been detected in the region under investigation. The results have shown that NBC rings mainly propagate into the Caribbean Sea along two principal pathways (near $12^{\circ} \mathrm{N}$ and $17^{\circ} \mathrm{N}$ ) in the ring translation corridor. Thus, rings following the southern pathway in the fallwinter period can enter through very shallow southern straits as non-coherent structures. A different behavior is observed near the northern pathway $\left(\sim 17^{\circ} \mathrm{N}\right)$, where NBC rings are thought to have a coherent structure during their squeezing into the eastern Caribbean, i.e. conserving the principal characteristics of the incident rings. We attribute this difference in the rings' behavior to the vertical scales of the rings and to the bottom topography features in the vicinity of the Lesser Antilles.
\end{abstract}

Keywords. Oceanography: general (Equatorial oceanography; Remote sensing and electromagnetic processes) Oceanography: physical (Eddies and mesoscale processes)

\section{Introduction}

The North Brazil Current constitutes one of the principal elements of the ocean circulation in the western Tropical Atlantic (Fig. 1). As is known from direct ship and satellite ob-

Correspondence to: S. N. Bulgakov

(sbulgako@cencar.udg.mx) servations, the North Brazil Current sheds anticyclonic rings near approximately $6^{\circ}-8^{\circ} \mathrm{N}$, with an average frequency of 69 per year (Goni and Johns, 2001, 2003; Garzoli et al., 2003; Jochum and Malanotte-Rizzoli, 2003; Johns et al., 2003; Richardson, 2005; Fratantoni and Richardson, 2006). Due to the effect of existing systems of currents (North Equatorial Current, Guyana Current), $\beta$-effect and the trade winds, these NBC rings (NBCR) travel in the NW direction, transporting water with different characteristics from the South Atlantic into the Caribbean Sea through the Lesser Antilles (LA), contributing to the exchange of mass and momentum with the surrounding waters. The characteristic scale of these NBCR (about $R=150 \mathrm{~km}$ radius) is much larger than the characteristic width $(40 \mathrm{~km})$ of the LA straits. Therefore, it is not obvious which kind of interaction could take place of these large rings and small straits.

A pioneering theoretical study of the rings-straits interaction issue was performed by Simmons and Nof (2002). An analytical and numerical investigation was conducted based on solving vertically integrated continuity and $x$-momentum equations. Collision of the NBC rings with the single and multiple gap systems was forced by $\beta$-effect and advection. These simulations revealed that, as NBCRs are weak (Rossby number $R o=0.2-0.4$ ) and large compared to the island scale $(L / R=0.5$, where $L$ is the characteristic island scale and $R$ is the radius of a typical NBCR), they are likely to enter the Caribbean Sea as coherent structures. Small and intense NBCRs, which are less common, are more likely to be broken up into a number of smaller structures.

A specific NBCR experiment was set up during 19982001. The observation program consisted of hydrographic and direct-velocity ADCP measurements (Wilson et al., 2002), an array of current meter and inverted echo sounder moorings (Johns et al., 2003; Garzoli et al., 2003), surface drifter and subsurface float observations (Fratantoni and Richardson, 2006), satellite measurements of the sea surface height (Goni and Johns, 2001, 2003), ocean color

Published by Copernicus GmbH on behalf of the European Geosciences Union. 


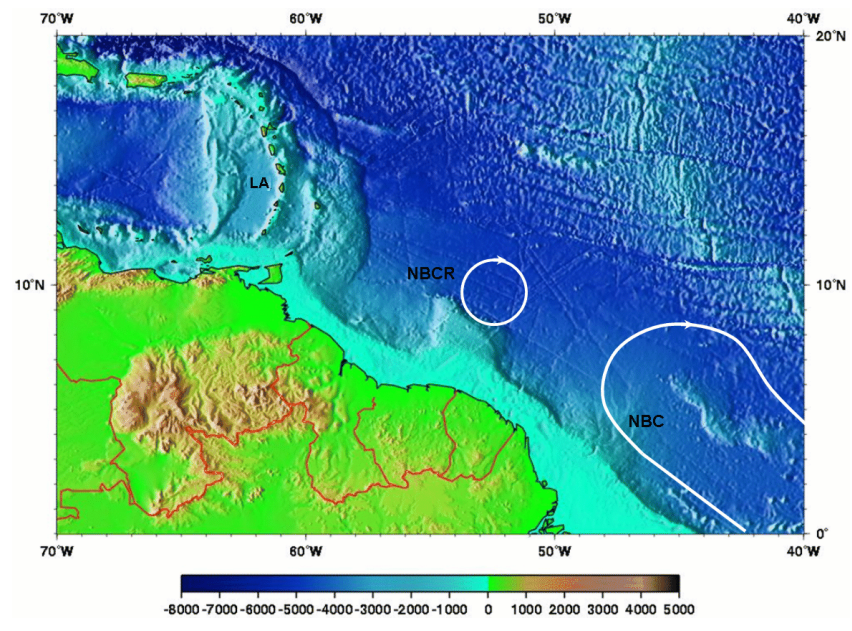

Fig. 1. Region of study in the western Tropical Atlantic $\left(70-40^{\circ} \mathrm{W}\right.$ and $0-20^{\circ} \mathrm{N}$ ) showing topography in the vicinity of the Lesser Antilles (LA), North Brazil Current (NBC) and shedded anticyclonic ring (NBCR).

(Fratantoni and Glikson, 2002) and sea surface temperature (Ffield, 2005).

A general bimodal and seasonal NBCR structure was detected in the region under study, showing a large (with typical maximum radius of $150 \mathrm{~km}$ ) and deeply penetrating ring formation (to depths of $2000 \mathrm{~m}$ ) during the fall and early winter months, while smaller and shallower rings tend to occur in spring and summer (Wilson et al., 2002; Johns et al., 2003).

Available altimetry data results analysis (Andrade and Barton, 2000; Goni and Johns, 2001, 2003) has indicated that few rings (approximately one out of six) penetrate the Caribbean Sea intact through the southern Lesser Antilles. The ensemble of ring trajectories is closely parallel to the 500-m isobaths. Most NBC rings tend to veer from their generally northwestward trajectories to the north as they approach the Tobago-Barbados Ridge, forming a ring translation corridor.

The SeaWiFS imagery, with a combination of the satellitetracked surface drifters, was analyzed by Fratantoni and Glikson (2002). It was noted that east of $58^{\circ} \mathrm{W}$ the rings with well-defined cores of midocean lifeless water surrounded by highly productive Amazon water are generally easy to visualize. West of this longitude the surface color expression gradually erodes. Therefore, information from surface drifters was processed to analyze the behavior of the rings in the vicinity of the LA. As the drifters generally had lost the characteristics of the incident vortices, it was concluded that there was no evidence that the observed rings penetrated the Caribbean Sea as coherent structures, that is, just some fractions of the ring's core detected by the initially looped drifters were observed entering the passages of the LA.

Richardson (2005), using data obtained from more than two hundred near-surface drifters, has concluded that anticy- clones in the eastern Caribbean are thought to be formed by the anticyclonic vorticity derived from NBC rings. Vorticity of ring remnants enters through island passages and is probably amplified by the anticyclonic shear on the northern side of the Caribbean Current jets.

Fratantoni and Richardson (2006) observed the evolution of $10 \mathrm{NBC}$ rings through the use of near surface $(15 \mathrm{~m})$ drifters and deeper $(250 \mathrm{~m}, 550 \mathrm{~m}$ and $900 \mathrm{~m})$ float observations. They found out that half of the rings followed a northward path parallel to the LA with no frontal collision with the island chain, while the remaining rings propagated westward south of Barbados. It was reported that the majority of the surface drifters (18 from 25) and near surface floats (5 from 7) for both types of the rings were observed entering the Caribbean eventually, but their looping stopped before reaching the Antilles island arc. Therefore, it was concluded that there is no evidence that NBC rings can enter the Caribbean Sea intact, that is as a coherent vortex preserving the same core properties as an incident ring. Only filaments of ring core fluid succeed in entering the eastern Caribbean.

However, some numerical simulations (Murphy et al., 1999; Carton and Chao, 1999; Barnier et al., 2001; Garraffo et al., 2003) and previously cited satellite altimeter observations suggest that some NBC rings do somehow pass intact through the narrow passages of the LA. In particular, the results described in Garraffo et al. (2003), based on a high-resolution $(6 \mathrm{~km})$ Miami isopycnal coordinate model, indicate that as the rings approach the Lesser Antilles, some of them appear to enter the Caribbean nearly intact. Some rings interact and merge with others possessing westwardpropagating wave-like features or a percentage of the rings separates and enters the Caribbean. The rings that enter the Caribbean, having diameters larger than the Lesser Antilles' passage widths, generally go through several passages at the same time and recombine in the lee of the islands. A larger percentage of shallow (37\%) and intermediate (43\%) rings move into the Caribbean than the deep (14\%) and subsurface (28\%) rings do. This suggests that the deep and subsurface rings, having the deepest reaching velocity structures, tend to be more influenced by the island arc topography and are less able to penetrate the Caribbean. A predominance of an intermediate and deep ring generation during the first half of the year was confirmed.

Thus, we can see that there is some kind of discrepancy between the results of the analysis of the previously cited altimetry data, numerical results and Lagrangean observations studying NBC ring structure and the evolution in the vicinity of the Lesser Antilles. A motivation of the present study is the usage of objective analysis methods usually applied for an image analysis to clarify the question (Simmons and Nof, 2002) of whether the NBC rings generally enter the Caribbean Sea as coherent or non-coherent structures.

The term "coherent" is used here as an attribute of the physical quantities which can be described in terms of waves: energy, wavelength and a fixed phase velocity. 
The characteristics of coherent and non-coherent ring structures are studied through Okubo-Weiss parameter calculations, time-longitude Hovmöller diagrams of the sea surface height, two-dimensional Radon transforms and twodimensional Fourier transforms.

\section{Data and methods}

The merged (TOPEX/Poseidon, Jason-1 and ERS-1,2) data used in this study were produced by SSALTO/DUACS (Developing Use of Altimetry for Climate Studies) and distributed by AVISO (Archiving Validation and Interpretation of Satellite Oceanographic data). These data were exposed to all standard corrections and objective time-space interpolation to build 7-day SHA fields on a $0.3^{\circ} \times 0.3^{\circ}$ grid. For further details, see the DUACS handbook (http://www.jason.oceanobs.com/documents/donnees/ duacs/handbook_duacs.pdf). The sea height anomaly (SHA) values were based on the 1993-2004 mean.

Available altimeter data over a continuous period of 12 years were processed by applying commonly used image analysis techniques (Challenor et al., 2001, 2002; Whitehead et al., 2003; Muzylev et al., 2005): band-pass filtering, in order to highlight the signal of NBC rings propagation, OkuboWeiss parameter calculations, to identify NBC rings, the twodimensional Radon transform (2D-RT), to objectively calculate the speed of the dominant signal in Hovmöller plots, the two-dimensional Fourier transform (2D-FT), which yields different spectral components of longitude-time plots and which appear as peaks in the frequency-wave number domain.

Specifically, we performed an estimation of the OkuboWeiss parameter (Okubo, 1970; Weiss, 1991) based on altimetry data and geostrophic velocity calculations as follows:

$R=-\frac{1}{2}\left[\left(\frac{\partial u}{\partial x}\right)^{2}+\left(\frac{\partial v}{\partial y}\right)^{2}-2 \frac{\partial u}{\partial y} \frac{\partial v}{\partial x}\right]$.

This parameter represents a balance between the magnitudes of vorticity and deformation. The value of $R=5.3 \times 10^{-12} \mathrm{~s}^{-2}$ was chosen experimentally for the NBC ring identification, according to the method proposed by Isern-Fontanet et al. (2003).

The two-dimensional Fourier transform highlights the different spectral components of the longitude-time plots, which appear as peaks in the spectrum in the wave number and frequency domain, that is, for an image $s(m \Delta x, n \Delta y)$ of $M \times N$ pixels, where $(m, n)$ are the pixel indices and $(\Delta x, \Delta y)$ are the resolutions in the $\mathrm{x}$ - (longitude) and $\mathrm{y}$ (time) directions, the 2D-FT is given by

$s\left(f_{x}, f_{y}\right)=\Delta x, \Delta y \sum_{m=1}^{M} \sum_{n=1}^{N} s(m \Delta x, n \Delta y) e^{-j 2 \pi\left(f_{x} \Delta x+f_{y} \Delta y\right)} \cdot(2)$
It is computed on a discrete grid $s\left(p \Delta f_{x}, q \Delta f_{y}\right)$, where $p=1, \ldots, M$ and $q=1, \ldots, N$ with frequency or wave number resolutions $\Delta f_{x}$ and $\Delta f_{y}$, showing both the amplitude and phase of each spectral component. Details of the 2D-FT can be found in Brigham (1988).

When the analysis is focused on the propagation speed rather than on the wavelength and period characteristics, the Radon transform is more appropriate (Deans, 1983). The two-dimensional Radon transform at a given angle $\theta$ is a projection of an image (the longitude-time plot) along a direction normal to $\theta$ :

$$
p\left(x^{\prime}, \theta\right)=\int_{y^{\prime}} f(x, y) \mid \begin{aligned}
& x=x^{\prime} \cos \theta-y^{\prime} \sin \theta \\
& y=x^{\prime} \sin \theta+y^{\prime} \cos \theta
\end{aligned} d y^{\prime} .
$$

Thus, computing the 2D-RT of the Hovmöller plot for different values of $\theta$ is equivalent to an objective estimate of the speed of the predominant propagating signal. These speeds that show a peak in the Radon energy could be computed by multiplying the $\tan \theta$ by the ratio of the time-longitude resolution (Challenor et al., 2001, 2002)

$v=37 \cos \varphi \cdot \tan \theta$.

Other sources of information, such as SeaWiFS (Sea viewing Wide Field Spectrometer) chlorophyll- $a$ and Global Drifter Program (GDP) data, have been used to complement SHA data. The SeaWiFS level-3 data product for the period 19972004, distributed by Goddard Distributed Flight Center, consists of calibrated, atmospherically corrected 8-day data and is stored in a global, equal-area grid $9 \times 9 \mathrm{~km}^{2}$. More details regarding the SeaWiFS instruments, calibration methods, and data processing can be found in McClain et al. (1998). The sole use of SeaWiFS imagery in the present study is for identifying NBC rings and the corridor of their movements.

Global Drifter Program data processed and distributed by Atlantic Oceanographic and Meteorological Laboratory (NOAA) as a component of NOAA's Global Ocean Observing System (GOOS) and Global Climate Observing System (GCOS) are available starting from 1979 up to the present (http://www.aoml.noaa.gov/phod/dac/dacdata.html). These drifters had their drogues centered at a $15-\mathrm{m}$ depth to measure mixed layer currents. Data obtained from drifting buoys was quality controlled and optimally interpolated to uniform 6-h interval trajectories (Hansen and Poulain, 1996; Lumpkin and Pazos, 2006). The drogue-on drifter data were used for verifying satellite observations.

\section{Results}

First of all, the root-mean-square (RMS) of the sea height over the region under study was calculated for the period of 1993-2004 (Fig. 2, top). The eddy rich regions with the highest sea height variability correspond to the NBC retroflection and the central Caribbean Sea. The band of elevated 

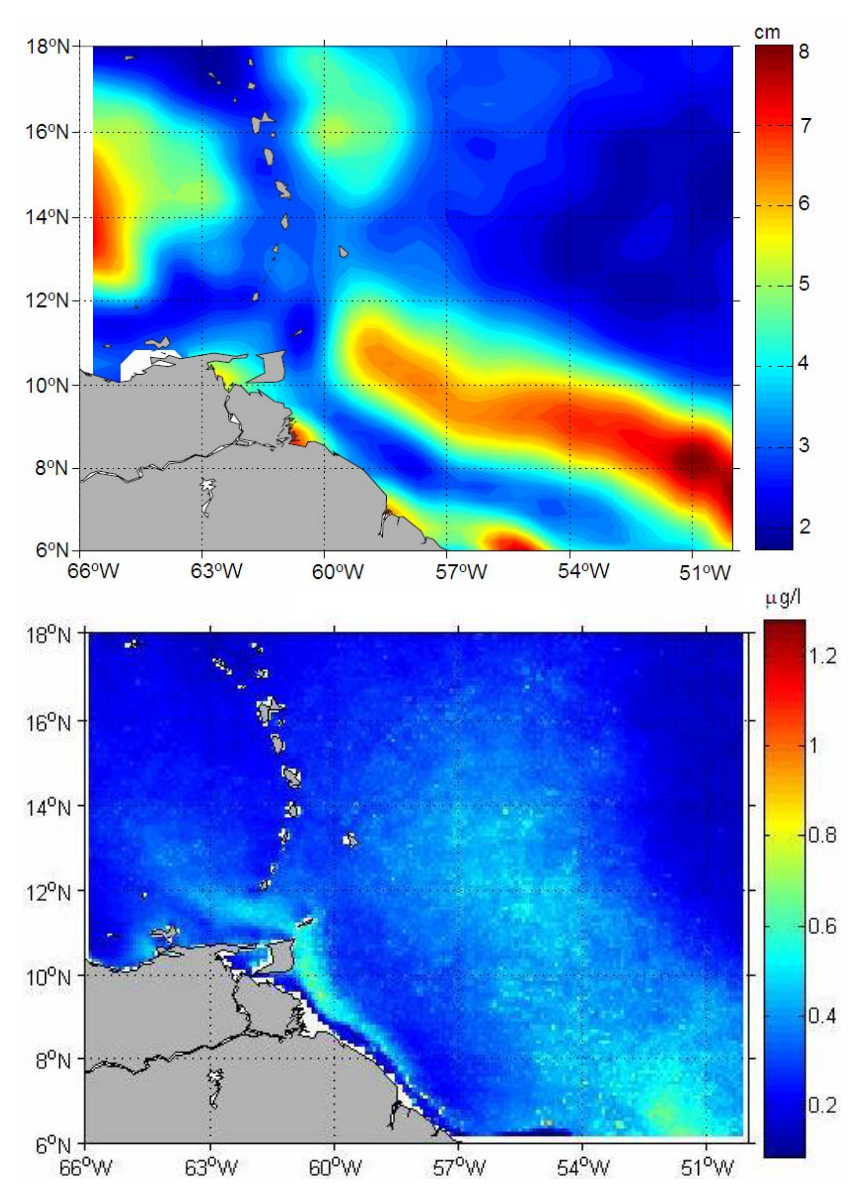

Fig. 2. Root-mean square of SHA data (in $\mathrm{cm}$ ) for the period of 1993-2004 (top) and chlorophyll- $a$ mean (in $\mu \mathrm{g} / \mathrm{l}$ ) for the period of 1997-2004 (bottom).

sea height variability along the coast of South America and the RMS peak near $15^{\circ}-17^{\circ} \mathrm{N}$ defines the northern pass of the ring translation corridor (Goni and Johns, 2003), along which the NBC rings travel as they propagate towards the LA. The lack of significant RMS values in the vicinity of the Arcs of the Lesser Antilles, where tidal errors contaminate the altimetric signal, does not allow for the identification of characteristic pathways of NBC rings or their remnants across the islands into the Caribbean Sea. Additionally calculated mean chlorophyll- $a$ data (Fig. 2, bottom) allows us to observe the chlorophyll intrusion near the southern pathway south of $12^{\circ} \mathrm{N}$. Chlorophyll- $a$ reached Orinoco River plume imposed here contributes to the color contrast and NBCR pathway identification.

The bimodal and seasonal structures of the movement of NBCR can be illustrated by the Okubo-Weiss parameter distribution. Figure 3 shows every 7-day position of the selected $R$-parameter value associated with the rings propagation to the island arc. That is, Fig. 3 (top) illustrates the NBC rings concentration along the northern pathway (blue arrow)
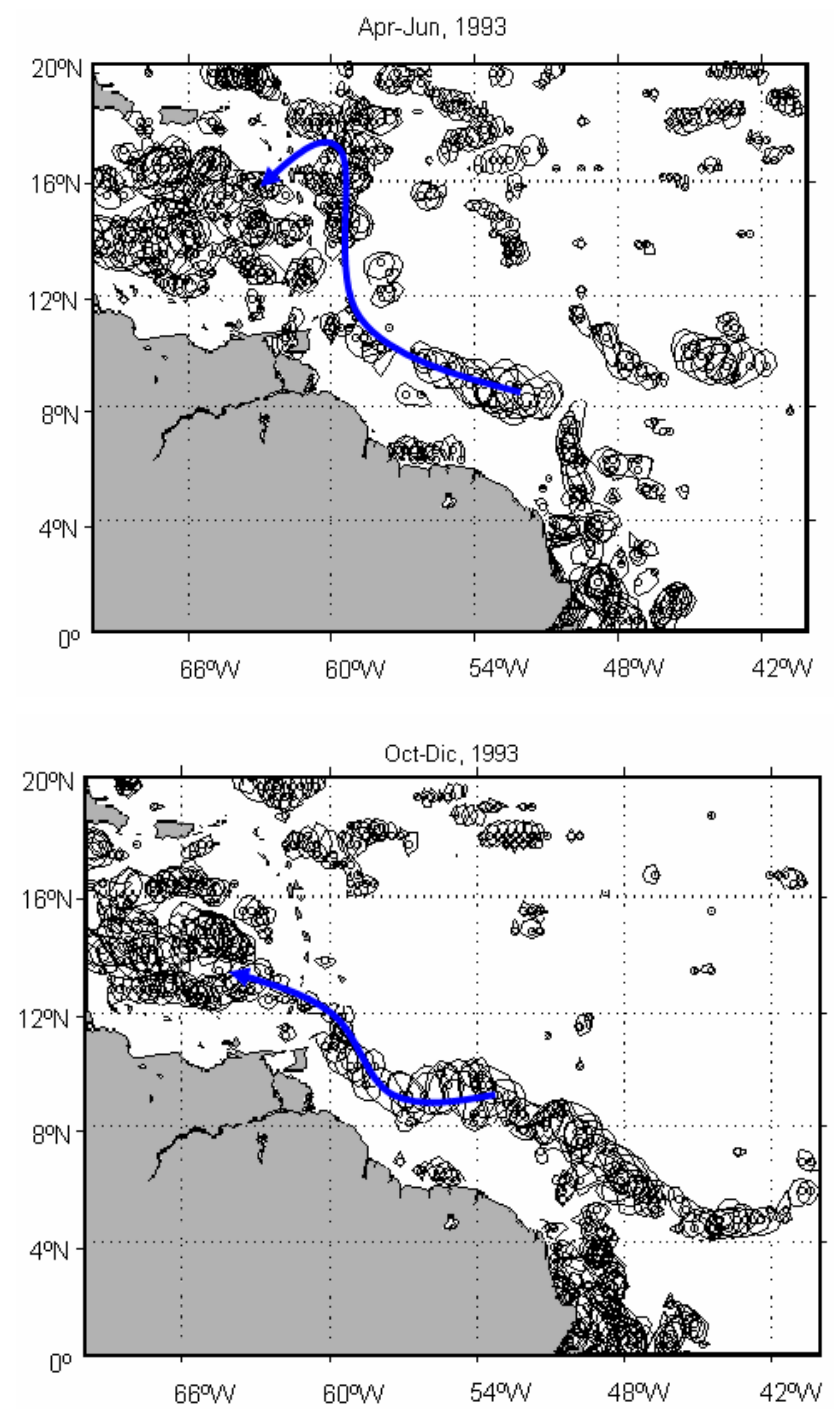

Fig. 3. Okubo-Weiss parameter $\left(R=5.3 \times 10^{-12} \mathrm{~s}^{-2}\right)$ distribution during April-June 1993 (top) and October-December 1993 (bottom). Positions of the rings every 7 days are shown by circles. Characteristic pathways of NBCR tracked every 7 days from image to image are shown by blue arrows.

during spring-summer 1993, while the southern pathway is dominant for the fall-winter months of 1993 (Fig. 3, bottom). The similar bimodal and seasonal structures were observed during the other years. Therefore, two latitudes $\left(12^{\circ} \mathrm{N}\right.$ and $17^{\circ} \mathrm{N}$ ) in the ring translation corridor were chosen for further data comparison, although all calculations were made for every $1^{\circ}$ of the latitude.

The longitude-time (Hovmöller) diagrams presented in Fig. 4 are generally used for studying the east-west signal propagation. As can be seen, the signal propagates continuously along $17^{\circ} \mathrm{N}$ through the LA. However, this signal does not propagate continuously near the southern pathway $12^{\circ} \mathrm{N}$, showing steep changes near the Arcs of Antilles (near 

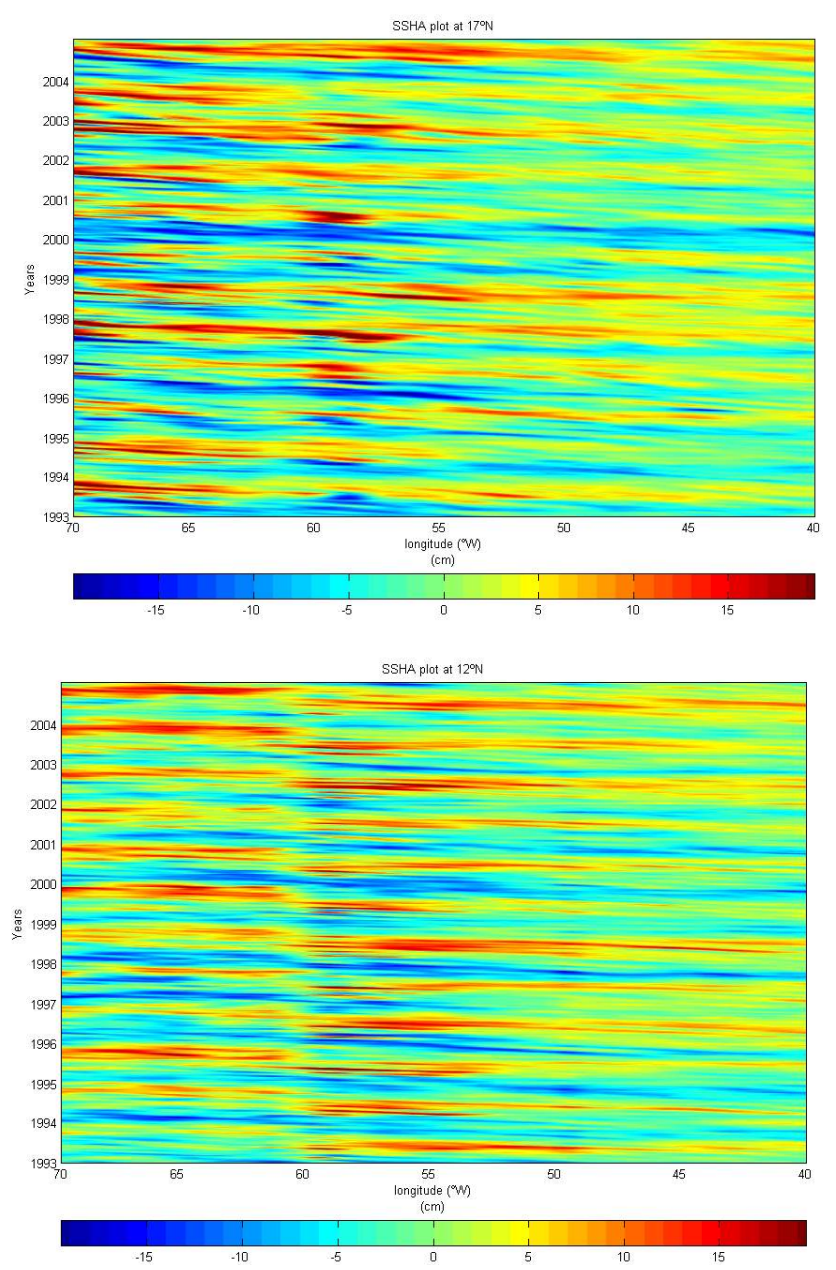

Fig. 4. Hovmöller diagrams of SHA at $17^{\circ} \mathrm{N}$ (top) and at $12^{\circ} \mathrm{N}$ (bottom) before filtration.

$\left.60^{\circ} \mathrm{W}\right)$. Another special feature of the Hovmöller diagrams is that an annual signal is dominant here. Therefore, this data was band-pass (from 1 to 6 months) filtered to observe the NBC rings propagation. As can be seen from Fig. 5 (top), a correspondence between incident and refracted signals could be observed near $17^{\circ} \mathrm{N}$, where the signal propagation character is preserved. On the contrary, the signal along $12^{\circ} \mathrm{N}$ (Fig. 5, bottom) decayed significantly, in close contact with the island arc (after $60^{\circ} \mathrm{W}$ ). This feature could be related to a different character of bottom topography patterns (Fig. 6, bottom) for $12^{\circ} \mathrm{N}$ latitude, before and after the island arc.

Based on the filtered Hovmöller diagrams, we performed an estimation of the 2-dimensional Radon transform. Figure 7 illustrates the angle (in other words, speed) of the maximum energy propagation in the northwestward direction, $6^{\circ}$ of the longitude before (solid line) and after (dashed line) the LA for $17^{\circ} \mathrm{N}$ latitude (top plot) and $12^{\circ} \mathrm{N}$ (bottom plot). One can see that correspondence is observed for the signal propagating through $17^{\circ} \mathrm{N}$ (Fig. 7, top plot), where it almost main-
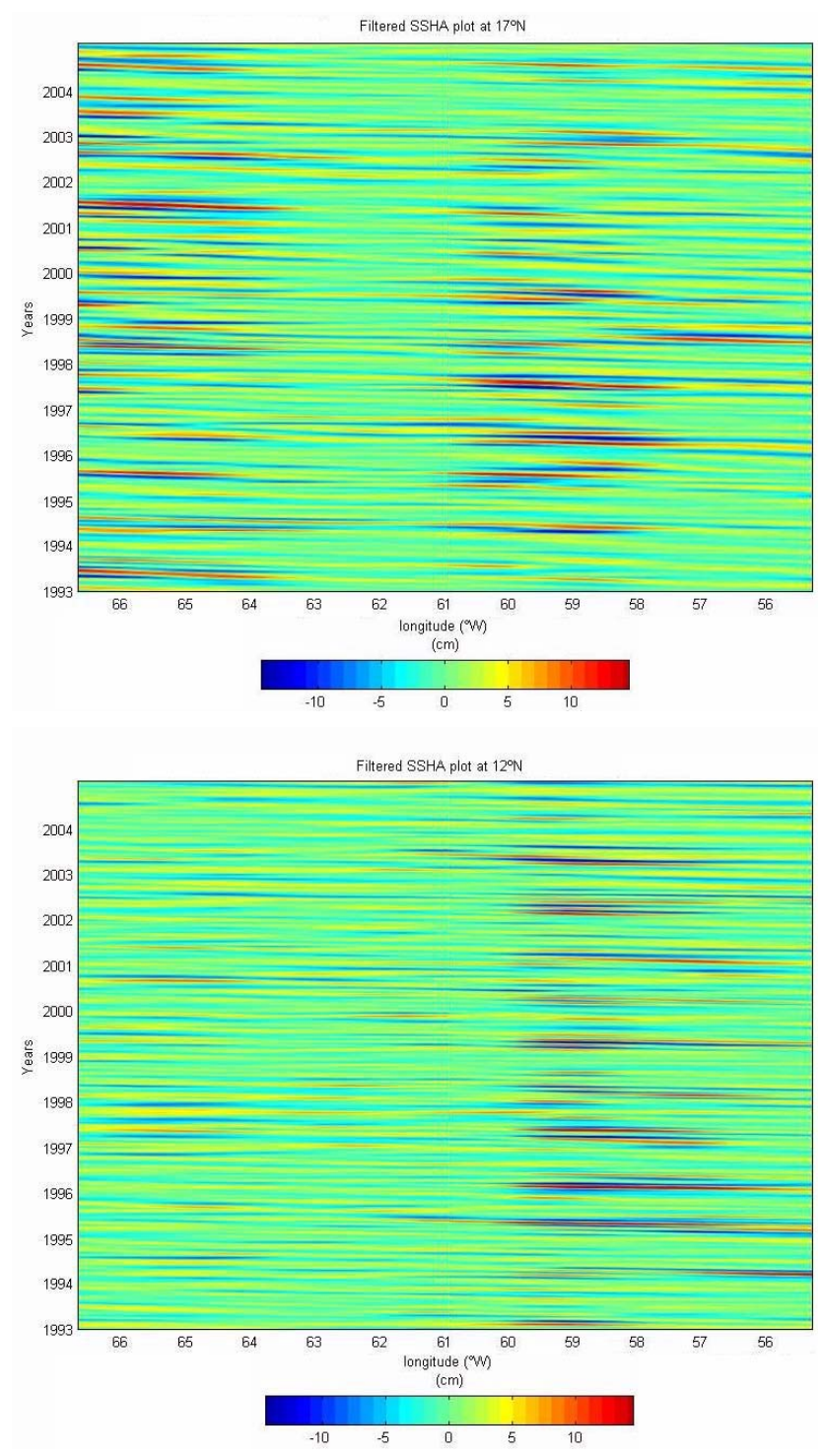

Fig. 5. Hovmöller diagrams at $17^{\circ} \mathrm{N}$ (top) and $12^{\circ} \mathrm{N}$ (bottom) after bandpass (1-6 months) filtering.

tains its speed $(20 \mathrm{~km} /$ day $)$ and energy values. In contrast, in northwest propagation the energy value is decreased significantly at latitude $12^{\circ} \mathrm{N}$ (Fig. 7, bottom), probably due to the dissipation by the shoaling topography. The velocity values were changed here from 12 to $16 \mathrm{~km} /$ day. These velocity values greatly exceed the velocity of the first two modes of Rossby waves ( $4 \mathrm{~km} /$ day and $3.5 \mathrm{~km}$ /day correspondingly) predicted by the linear theory

$\omega_{n}=-\frac{\beta k}{k^{2}+l^{2}+R_{n}^{-2}}$,

where $\omega_{n}$ is a frequency of $n$-mode of Rossby wave, $\beta$ is a Coriolis parameter variation; $(k, l)$ are the wave numbers in the $(x, y)$ directions and $R_{n}$ is the Rossby radius of deformation for the $n$-mode. 


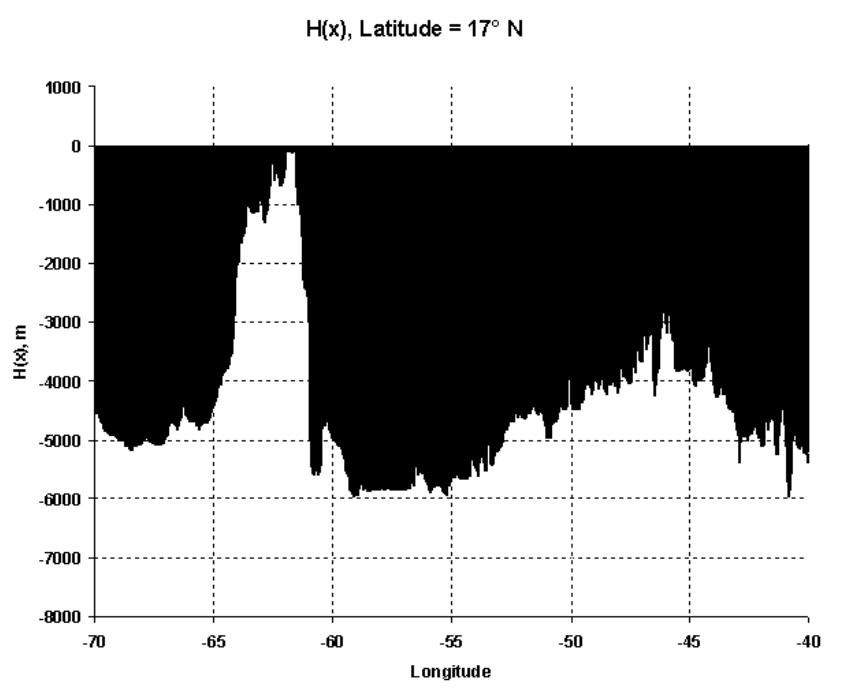

$H(x)$, Latitude $=12^{\circ} \mathrm{N}$

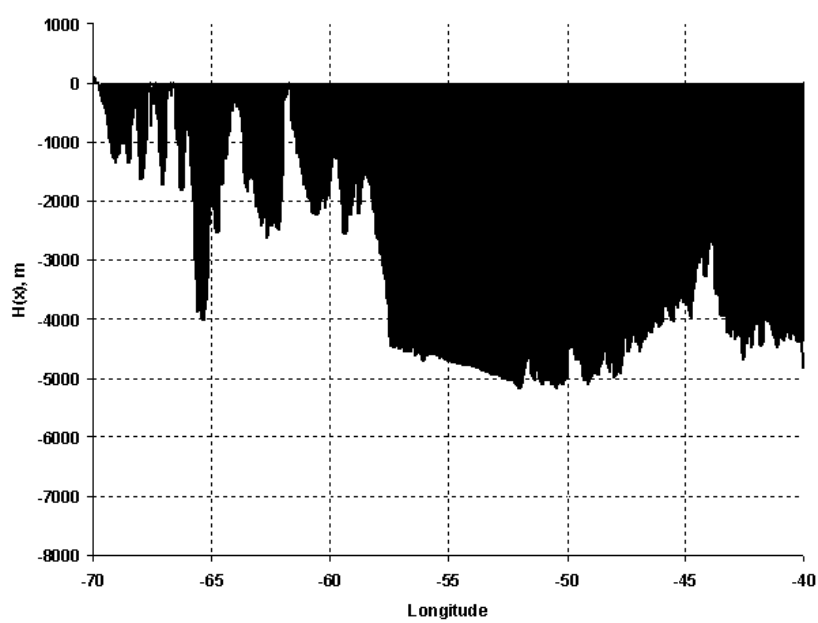

Fig. 6. Bottom topography (m) along $17^{\circ} \mathrm{N}$ (top) and along $12^{\circ} \mathrm{N}$ (bottom).

A two-dimensional Fourier transform (2D-FT) for all latitudes was realized, as well as for areas before and after LA. From Fig. 8 (top), one can see that wave number/frequency diagrams are more or less equivalent for latitude $17^{\circ} \mathrm{N}$ for the northern pathway, for areas before and after LA, whereas these diagrams are somewhat different for the southern pathway near $12^{\circ} \mathrm{N}$ (Fig. 8, bottom). A similar behavior could be attributed to a majority of other latitudes. Thus, we can conclude that quasi-coherent (near $17^{\circ} \mathrm{N}$ ) and non-coherent structures are present in the region under study.

As an example, Fig. 9 shows the behavior of the two rings in the vicinity of the Lesser Antilles, using satellite-tracked near-surface drifter's trajectories in combination with SHA images. The bottom figure illustrates that the GDP drifter near $10^{\circ} \mathrm{N}$ ceased looping before it reached the Antilles arc and therefore lost the characteristics of a vortex during its
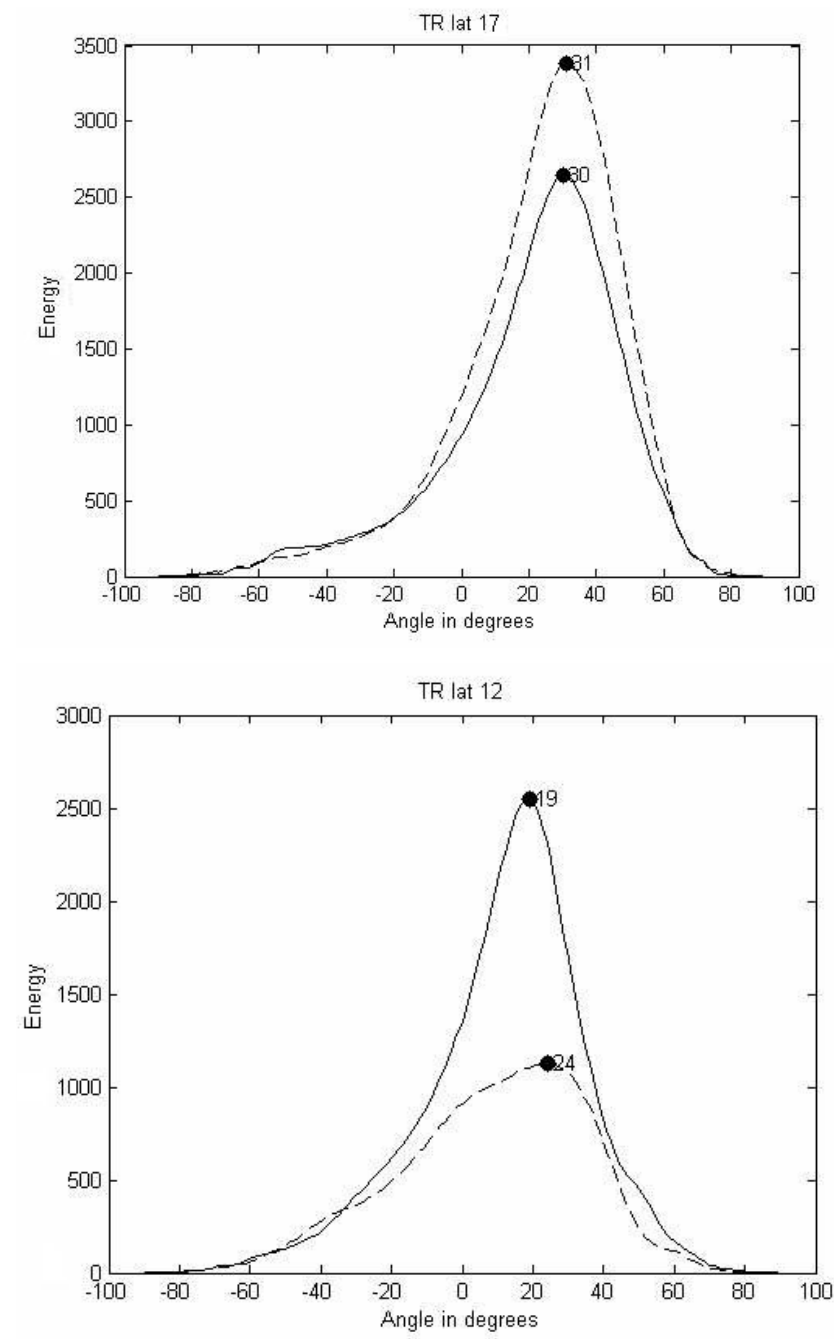

Fig. 7. Radon transform at $17^{\circ} \mathrm{N}$ (top) and at $12^{\circ} \mathrm{N}$ (bottom) before (solid line) and after (dashed line) the LA.

propagation near the southern pathway. The drifter left the ring and subsequently entered the Caribbean, while the ring disappeared in the AVISO gridded field by failing between satellite passes. It is quite possible that this ring was destroyed through an interaction with the abrupt topography of the Lesser Antilles. Only its remnant was seemingly advected by the mean flow in which it was embedded. In contrast, it seems that both SHA and the drifter trajectory illustrate the westward leakage of the merged anticyclonic anomaly through the island arc near $15^{\circ}-17^{\circ} \mathrm{N}$ (Fig. 9, top). This suggests that the ring maintained an organized circulation while squeezing directly across the island arc, as had been predicted by the Simmons and Nof (2002) theory.

Presently, there is not much direct evidence obtained from drifters positioned in NBC rings, of an anticyclone formation inside the Caribbean. Richardson (2005) has demonstrated how a single drifter looped and translated towards the island arc, passed between the Dominica and Guadalupe Islands, 

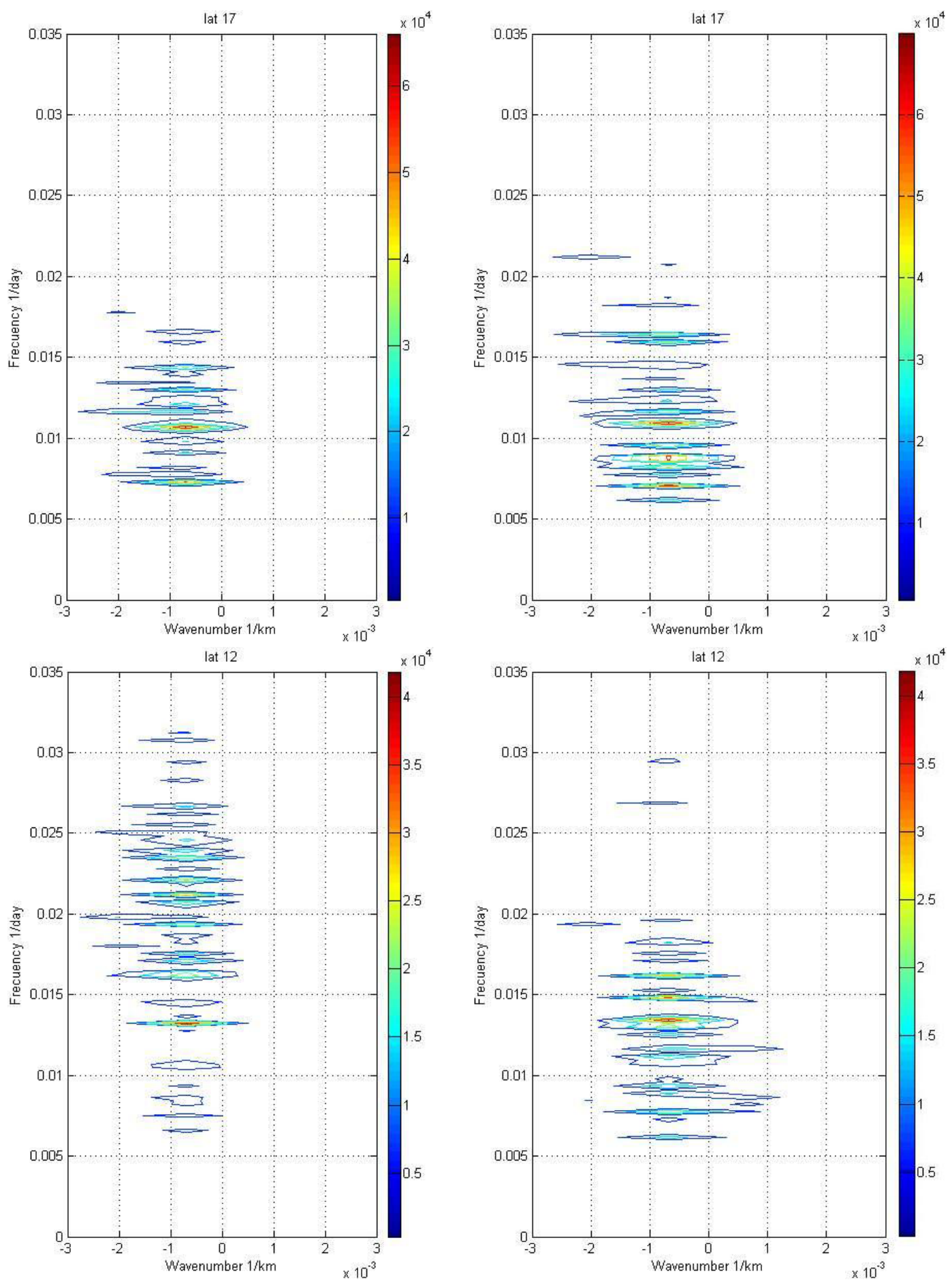

Fig. 8. Fast Fourier transform at $17^{\circ} \mathrm{N}$ (top) and at $12^{\circ} \mathrm{N}$ (bottom) before (left) and after (right) the LA.

making a looping immediately west of the island arc inside the Caribbean. Loopers (drifters making two or more consecutive loops) and non-loopers are examined separately by Lumpkin and Garzoli (2005), with pathways generally supportive of the hypothesis being presented in this manuscript.
It was reported that 6 loopers from 32 and 14 of the 16 nonloopers entered the Caribbean Sea south of Puerto Rico. 


\section{MAY-16-2002 to JUN-16-2002}

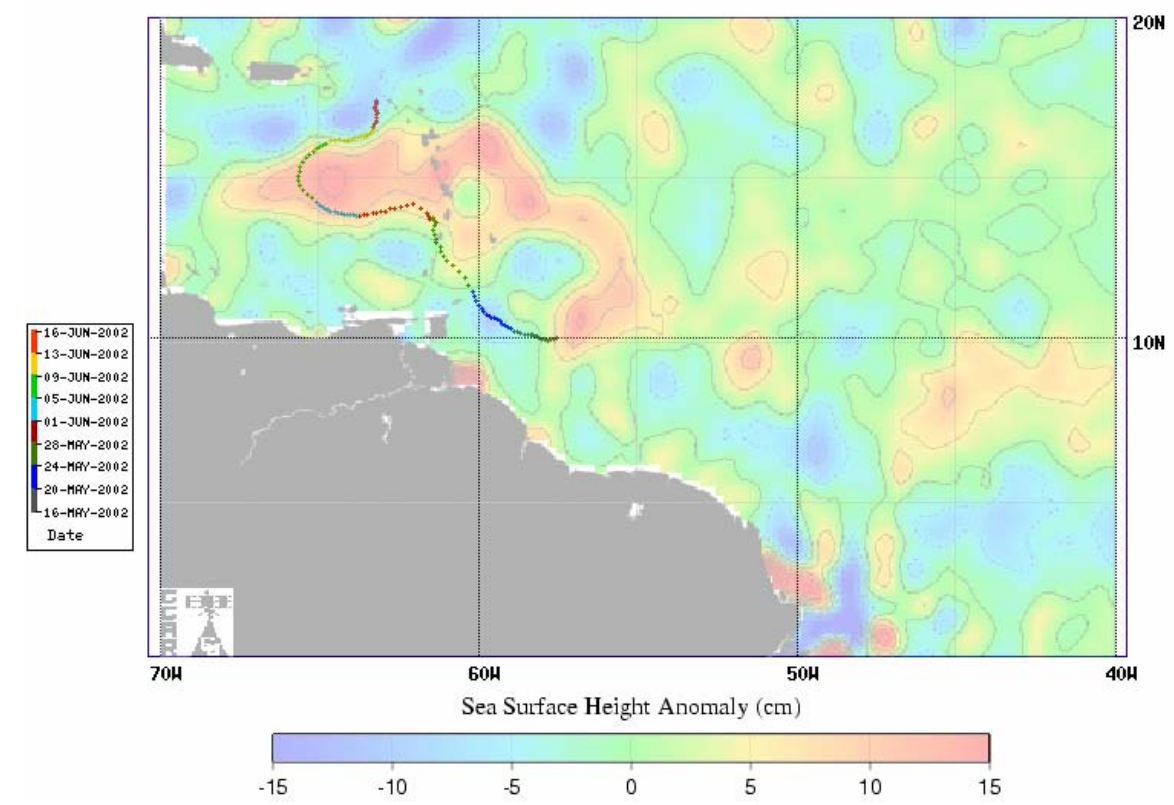

NOV-18-1999 to DEC-19-1999

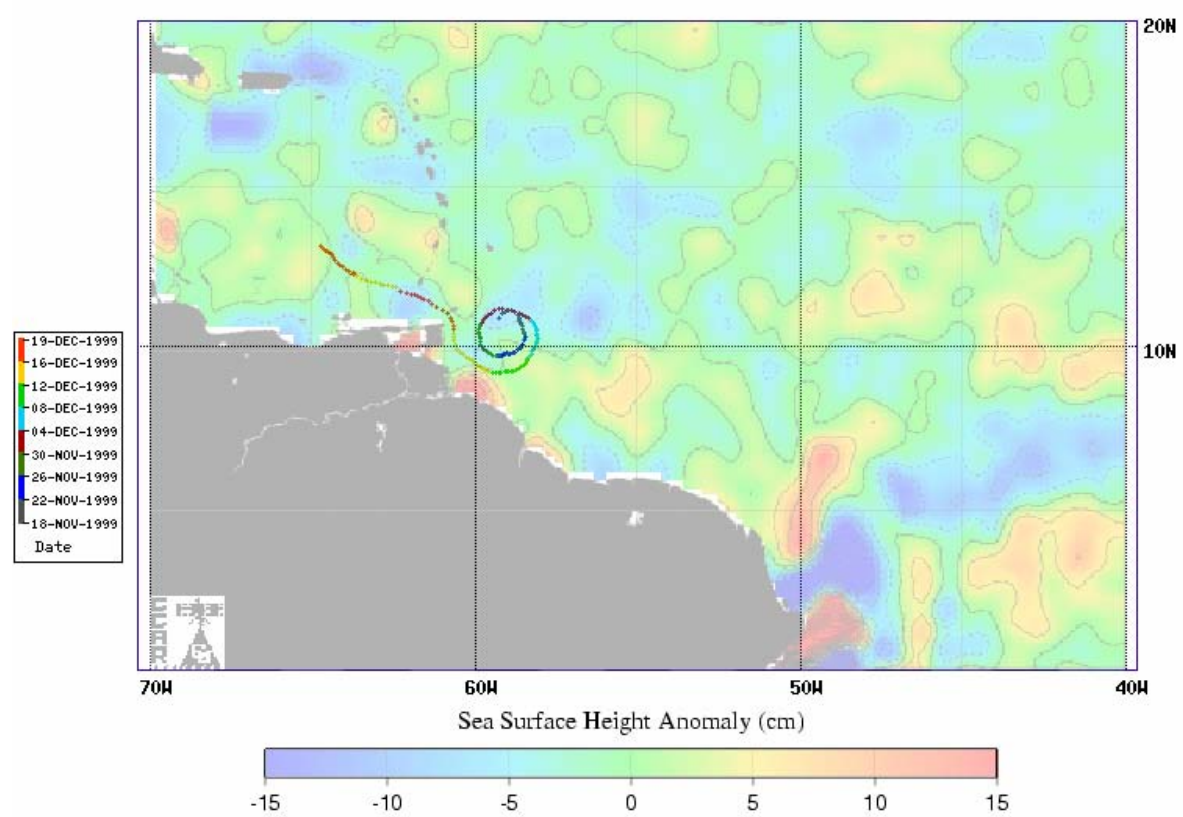

Fig. 9. Examples of altimetry SHA data and GDP trajectories showing quasi-coherent near $15-17^{\circ} \mathrm{N}$ (top) and non-coherent near $10-12^{\circ} \mathrm{N}$ (bottom) propagation of rings through the LA.

\section{Summary and conclusions}

This study has examined the dynamics of the NBCRs in the vicinity of the Lesser Antilles based on the analysis of a 12year long altimeter and 8-year long SeaWiFS data, in combi- nation with satellite-tracked surface drifters' data for investigating the issue of ring-gap interaction.

It was recognized that the majority of the NBC rings do not enter the Caribbean Sea as coherent structures, as their signals are changed significantly upon reaching the island 
arc. These are destroyed by the LA topography, and only filaments of the rings are able to enter the eastern Caribbean.

The most significant finding is that the signal propagation near $17^{\circ} \mathrm{N}$ is a probable candidate for proving that the NBC rings conserve coherent structures during their propagation through the arc of the LA. Though an identification of the NBC rings in the SHA signal is not a trivial issue, we speculate that an NBC ring can enter the Caribbean Sea near $17^{\circ} \mathrm{N}$ intact, that is, as a coherent vortex containing the same core properties as an incident ring.

It could be mentioned that deep rings formed during the fall and wintertime do not enter the Caribbean Sea through the shallow southern straits as coherent structures. On the contrary, shallow rings moving along the northern pathway could enter the eastern Caribbean as coherent structures through the deep-water passages. The rings that enter the Caribbean, having diameters larger than the Lesser Antilles passage widths, generally go through several passages at the same time and recombine in the lee of the islands, that is a behavior noted in Simmons and Nof (2002), precisely, as NBCRs are weak and large, they are likely to enter the Caribbean Sea as coherent structures. Rings that are small compared to islands are more likely to be broken up.

Thus, we can conclude that the ring movement through the Lesser Antilles into the Caribbean Sea along the northern trajectory is realized as quasi-coherent structures (with minimum changes of the main signal characteristics). On the contrary, along the southern trajectories NBC rings enter the eastern Caribbean as non-coherent structures with a displacement of the characteristics in the domain of low frequencies. Intrusion of the NBC rings' remnants into the Caribbean Sea along the southern trajectory is probably realized in the form of the surface remnants, because in the very thick upper layer GDP floats $(\sim 15 \mathrm{~m})$ generally lose the characteristics of the vortices during their propagation through the Arc of Antilles. For the northern trajectory these rings seem to enter deeper due to the general correspondence of the three types of data (altimetry, chlorophyll, floats).

Acknowledgements. The first author acknowledges financial support from the Consejo Nacional de Ciencia y Tecnologia (CONACYT, Mexico) for doctoral fellowship. This work was supported by CONACYT through the grant $46472-\mathrm{F}$ as well.. The original manuscript was greatly improved owing to comments from two anonymous reviewers. Special thanks to D. Nof and to S. Grodsky for their helpful suggestions. We appreciate the effort made by $\mathrm{S}$. Kemp who helped us with the English grammar. The altimeter products were produced by the CLS Space Oceanography Division as part of the Environment and Climate EU ENACT project (EVK2-CT2001-00117) and with CNES support. We thank the SeaWiFS team for providing chlorophyll data, AVISO for SHA data and AOML (NOAA) for buoys data.

Topical Editor S. Gulev thanks two referees for their help in evaluating this paper.

\section{References}

Andrade, C. A. and Barton, E. D.: Eddy development and motion in the Caribbean Sea, J. Geophys. Res., 105, 26 191-26 201, 2000.

Barnier, B., Reynaud, T., Beckmann, A., Boning, C., Molines, J.M., Barnard, S., and Jia, Y.: On the seasonal variability and eddies in the North Brazil Current: Insight from model intercomparison experiments, Prog. Oceanogr., 44, 195-230, 2001.

Brigham, E. O.: The fast Fourier transform and its applications, Prentice Hall, 448 p., 1988.

Challenor, P. G., Cipollini, P., and Cromwell, D.: Use of the 3D Radon transform to examine the properties of oceanic Rossby waves, J. Atmos. Oceanic Technol., 18, 1558-1566, 2001.

Challenor, P. G., Chipollini, P., Cromwell, D., Hill, L., Graham, D., and Robinson, S.: Characteristic of mid-latitude Rossby wave propagation from multiple satellite datasets, Int. J. Rem. Sens., 25(7-8), 1297-1302, 2002.

Carton, J. A. and Chao, Y.: Caribbean Sea eddies inferred from TOPEX/POSEIDON altimetry and a 1/6 degree Atlantic Ocean model simulation, J. Geophys. Res., 104, 7743-7752, 1999.

Deans, S. R.: The Radon transform and some of its applications, J. Wiley Publ., 204-217, 1983.

Ffield, A.: North Brazil Current rings viewed by TRMM Microwave Image SST and the influence of the Amazon Plume, Deep-Sea Res. I, 52, 137-160, 2005.

Fratantoni, D. M. and Glikson, D. A.: North Brazil Current Ring generation and evolution observed with SeaWiFS, J. Phys. Oceanogr., 32(3), 1058-1074, 2002.

Fratantoni, D. M. and Richardson, P. L.: The evolution and demise of North Brazil Current Rings, J. Phys. Oceanogr., 36(7), 12411264, 2006.

Garraffo, Z. D., Johns, W. E., Chassignet, E. P., and Goni, G. J.: North Brazil Current rings and transport of southern waters in a high resolution numerical simulation of the North Atlantic, in: Interhemispheric water exchange in the Atlantic Ocean, edited by: Goni, G. J. and Malanotte-Rizzoli, P., Elsevier Ocean. Series, 68, 375-410, 2003.

Garzoli, S. L., Ffield, A., and Yao, Q.: North Brazil Current Rings and the variability in the latitude of retroflection, in: Interhemispheric water exchange in the Atlantic Ocean, edited by: Goni, G. J. and Malanotte-Rizzoli, P., Elsevier Ocean. Series, 68, 357373, 2003.

Goni, G. J. and Johns, W. E.: A census of North Brazil Current rings observed from T/P altimetry: 1992-1998, Geophys. Res. Lett., 28(4), 1-4, 2001.

Goni, G. J. and Johns, W. E.: Synoptic study of warm rings in the North Brazil Current retroflection region using satellite altimetry, in: Interhemispheric water exchange in the Atlantic Ocean, edited by: Goni, G. J. and Malanotte-Rizzoli, P., Elsevier Ocean. Series, 68, 335-356, 2003.

Hansen, D. and Poulain, P.-M.: Quality control and interpolation of WOCE-TOGA drifter data, J. Atmos. Oceanic Technol., 13, 900-909, 1996.

Isern-Fontanet, J., Garcia-Ladona, E., and Font, J.: Identification of marine eddies from altimetric maps, J. Atmos. Oceanic Technol., 20, 772-778, 2003.

Jochum, M. and Malanotte-Rizzoli, P.: On the generation of North Brazil Current rings, J. Mar. Res., 61, 147-173, 2003.

Johns, W. E., Zantopp, R. J., and Goni, G. J.: Cross-gyre transport by North Brazil Current rings, in: Interhemispheric wa- 
ter exchange in the Atlantic Ocean, edited by: Goni, G. J. and Malanotte-Rizzoli, P., Elsevier Ocean. Series, 68, 411-441, 2003.

Lumpkin, R. and Garzoli, S. L.: Near-surface circulation in the Tropical Atlantic ocean, Deep-Sea Res. I, 52(3), 495-518, 2005.

Lumpkin, R. and Pazos, M.: Measuring surface currents with SVP drifters: the instrument, its data and some recent results, in: Lagrangian Analysis and Prediction of Coastal and Ocean Dynamics, edited by: Griffa, A., Kirwan, A. D., Mariano, A. J., Ozgokmen, T., and Rossby, T., Cambridge Univ. Press, 2006.

McClain, C. R., Cleave, M. L., Feldman, G. C., Gregg, W. W., Hooker, S. B., and Kuring, N.: Science quality SeaWiFS data for global biosphere research, Sea Technol., 39, 10-16, 1998.

Murphy, S. J., Hurlburt, J. E., and O'Brien, J. J.: The connectivity of eddy variability in the Caribbean Sea, the Gulf of Mexico and the Atlantic Ocean, J. Geophys. Res., 104, 1431-1454, 1999.

Muzylev, S. V., Bulgakov, S. N., and Duran-Matute, M.: Edge capillary-gravity waves on a sloping beach. Phys. Fluids, 17(4), 048103, doi:10.1063/1.1879052, 2005.
Okubo, A.: Horizontal dispersion of floatable particles in the vicinity of velocity singularities such as convergences, Deep-Sea Res., 17, 445-454, 1970.

Richardson, P. L.: Caribbean Current and eddies as observed by surface drifters, Deep-Sea Res. II, 52, 429-463, 2005.

Simmons, H. L. and Nof, D.: The squeezing of eddies through gaps, J. Phys. Oceanogr., 32, 314-335, 2002.

Weiss, J.: The dynamics of enstrophy transfer in two-dimensional hydrodynamics, Phys. D, 48, 273-294, 1991.

Wilson, D. W., Johns, W. E., and Garzoli, S. L.: Velocity structure of North Brazil Current rings, Geophys. Res. Let., 29(8), 1273, doi:10.1029/2001GL013869, 2002.

Whitehead, J. A., Timmermans, M. L. E., Lawson, W. G., Bulgakov, S. N., Zatarain, A. M., Medina, J. F. A., and Salzig, J.: Laboratory studies of thermally and/or salinity-driven flows with partial mixing, 1. Stommel transitions and multiple flow states, J. Geophys. Res. - Oceans, 108(C2), 3036, doi:10.1029/2001JC000902, 2003. 